\title{
A OPINIÃO DOS ESTUDANTES SOBRE AS EXIGÊNCIAS DA PRODUÇÃO NA PÓS-GRADUAÇÃO
}

\author{
DRA. VALDELAINE DA ROSA MENDES \\ Faculdade de Educação, Universidade Federal de Pelotas \\ (Pelotas - Rio Grande do Sul - Brasil) \\ E-mail: valrosamendes@uol.com.br
}

\section{MS. JACOB ALFREDO IORA}

Centro de Educação Física e Desportos, Universidade Federal de

Santa Maria (Santa Maria - Rio Grande do Sul - Brasil)

E-mail: jacobiora@ibest.com.br

\begin{abstract}
RESUMO
Este estudo teve como objetivo identificar quais são as repercussões das exigências de produtividade no campo acadêmico para os discentes de um curso de pós-graduação, e de que forma estas afetam objetiva e subjetivamente o seu cotidiano. Na investigação adotou-se a abordagem metodológica qualitativa, tendo como referência a busca da compreensão do objeto estudado e sua explicação na prática social (TRIVIÑOS, 2006). Optou-se pela realização de um estudo de caso, pelo entendimento de que esse tipo de pesquisa qualitativa seria a mais adequada para alcançar os propósitos das indagações levantadas. A delimitação do tempo e a mensuração quantitativa de índices de produção foram identificadas como as principais causas da precarização da formação em um curso de mestrado.
\end{abstract}

PALAVRAS-CHAVE: Pós-graduação; produção; Educação Física; pesquisa. 
Até os anos 1980, na Educação Física (EF) brasileira as interpretações sobre o comportamento humano sustentavam-se fundamentalmente nos conhecimentos das ciências biológicas. Nas duas últimas décadas do século $X X$, afloraram na área estudos e pesquisas cujo foco não estava somente no campo biológico, mas no campo das ciências humanas. Para além das questões anatômicas, fisiológicas e cinesiológicas, estes estudos pretendem analisar outras dimensões do comportamento humano, buscando compreendê-lo na sua historicidade a partir de aspectos sociais, econômicos, culturais e políticos.

As diferentes bases epistemológicas de interpretação da EF vão gerar conflitos na área que serão sentidos nos processos de formação, tanto em nível de graduação quanto de pós-graduação, desencadeando verdadeiros embates para definir, especificamente na pós-graduação, em qual área do conhecimento a EF deve estar localizada: nas ciências humanas, nas ciências da saúde ou nas áreas multidisciplinares.

Atualmente, na Coordenação e Aperfeiçoamento de Pessoal de Nível Superior (Capes), a EF, juntamente com a terapia ocupacional, a fisioterapia e a fonoaudiologia, forma uma subárea nas ciências da saúde. Para a criação ou conservação de cursos de pós-graduação as instituições seguem as determinações desse campo do conhecimento, no qual docentes precisam atender critérios de produtividade científica para credenciamento e permanência na pós-graduação. Essa é uma dificuldade para a área, pois todo um campo de estudos da EF, localizado nas ciências humanas, precisa submeter-se a critérios de produtividade que não contemplam suas características, demandas e necessidades.

Entretanto, a localização da EF, enquanto área do conhecimento, é apenas um entre os inúmeros problemas que se apresentam à produção científica no país. A exigência de produção no campo acadêmico tem sido denunciada por autores como Sguissardi (20 I 0), Silva Jr. e Sguissardi (2009), Silva Jr (20 I 0), Bosi (2006, 20 I I), Trein e Rodrigues (20 I I), Maués (2008), por ser a expressão, nas universidades brasileiras, das novas formas de exploração da força de trabalho, observadas no mundo nas últimas décadas e, no Brasil, mais fortemente a partir dos anos 1990.

Para compreender quais são as repercussões dessas demandas de produtividade no campo acadêmico realizou-se esta pesquisa, que teve como objetivo identificar qual a percepção dos discentes de um curso de pós-graduação sobre essas exigências na área, e como estas afetam objetiva e subjetivamente o seu cotidiano.

$\mathrm{Na}$ investigação adotou-se a abordagem metodológica qualitativa, tendo como referência a busca da compreensão do objeto estudado e sua explicação na prática social (TRIVIÑOS, 2006). As interrogações estabelecidas nesta pesquisa 
são explicitadas com base em uma fundamentação teórica, na qual o fenômeno é compreendido na sua totalidade, isto é, analisado a partir das variadas dimensões que o determinam.

Optou-se pela realização de um estudo de caso, pelo entendimento de que esse tipo de pesquisa qualitativa seria a mais adequada para alcançar os propósitos das indagações levantadas. Isto porque, o estudo de caso permite a combinação de diferentes estratégias de investigação para uma interpretação aprofundada do fenômeno analisado. De acordo com Stake (1983, p. 2 I), o caso "pode ser uma pessoa, mas frequentemente será um grupo de indivíduos, um programa ou algum esforço coletivo indeterminado".

O estudo foi realizado em um dos cursos de Mestrado em EF' da região sul do Brasil. Para o desenvolvimento da pesquisa foram levantados documentos do programa e realizadas entrevistas semiestruturadas. Os principais documentos utilizados foram os registros sobre a história e a constituição do referido curso.

Participaram das entrevistas sete estudantes lotados em todas as linhas de pesquisa do curso e que eram bolsistas do programa. ${ }^{2}$ Com isso, conseguiu-se apreender as percepções de acadêmicos pertencentes ao campo de estudos das ciências biológicas e das ciências humanas na EF sobre as exigências de produtividade. Entre os convidados a participar da investigação, apenas um estudante, que havia mudado de estado, não concedeu a entrevista. ${ }^{3}$

O Programa de Pós-graduação em EF aqui analisado encontra-se alocado em uma instituição pública do Brasil. Teve início no ano de 2007 e tem por finalidade a capacitação de recursos humanos por meio da formação de mestres em EF que atuam nos diversos espaços da área. De acordo com os documentos analisados, o curso pretende formar profissionais com qualificação para analisar a realidade, identificar questões científicas e realizar projetos de investigação que contribuam para o avanço do conhecimento na área da EF.

Outro propósito do programa é capacitar profissionais para a docência em ensino superior, uma atividade que atualmente possui como um de seus requisitos básicos a formação acadêmica em nível de mestrado ou doutorado. A instituição recebe alunos de todo o Brasil, mas a maioria dos acadêmicos é oriunda do estado do Rio Grande do Sul.

Este texto está divido em três partes. Na primeira parte encontra-se uma discussão sobre o caráter assumido pela forma de produção capitalista na atualidade.

\footnotetext{
I. Para evitar qualquer tipo de identificação, desnecessária aos propósitos da investigação, todos os nomes adotados no estudo são fictícios.

2. Foi um critério adotado para a escolha dos entrevistados

3. Para esse aluno foi proposta a realização da entrevista via skype, mas mesmo assim não participou da pesquisa.
} 
○ texto inicia com essa questão devido ao reconhecimento de que não é possível analisar a pós-graduação brasileira sem a conexão com os acontecimentos econômicos. No segundo momento há um debate sobre a produtividade exigida na vida acadêmica. São levantadas questões sobre o tipo de resultado científico valorizado na universidade e as implicações desta exigência para a formação acadêmica e para a vida social. No terceiro momento ocorre a análise da pesquisa de campo realizada junto aos pós-graduandos em EF.

\section{OS OBJETIVOS DO MERCADO NO TRABALHO UNIVERSITÁRIO}

De acordo com Peixoto (2003), no modo de produção capitalista o homem é reduzido a simples mão de obra e perde sua possibilidade de criar e imaginar, enfim, perde seu caráter primordial de agir consciente e livremente sobre o mundo. Por não ter outra forma de sobreviver, precisa vender sua força de trabalho e submeter-se às determinações dos proprietários dos meios de produção. Isso tudo se acentua numa sociedade que adere ao consumismo exacerbado e se pauta nos princípios do modelo neoliberal.

As crises afetam o modo de produção vigente de tempos em tempos e geram a cada momento de decadência da era capitalista a sua reestruturação. A cada crise a classe trabalhadora sofre consequências profundas. Nas últimas décadas, para atingir os objetivos do mercado, esse sistema tem estabelecido metas de produtividade aos trabalhadores cujos desdobramentos são a fragmentação da vida social, em especial, a dispersão temporal do trabalho e a destruição dos referenciais que balizavam a identidade de classe e as formas de luta de classes.

\footnotetext{
Observa-se, no universo do mundo do trabalho do capitalismo contemporâneo, uma múltipla processualidade: de um lado verificou-se uma desproletarização do trabalho industrial fabril, nos países de capitalismo avançado, com maior ou menor repercussão em áreas industrializadas do Terceiro Mundo.[...] Mas, paralelamente, efetivou-se uma expressiva expansão do trabalho assalariado, a partir da enorme ampliação do assalariamento no setor de serviços; verificou-se uma significativa heterogeneização do trabalho, expressa também através da crescente incorporação do contingente feminino no mundo operário; vivencia-se também uma subproletarização intensificada, presente na expansão do trabalho parcial, temporário, precário, subcontratado, "terceirizado", que marca a sociedade dual no capitalismo avançado. (ANTUNES, 2002, p. 49, grifos do autor)
}

Desde os anos 1990, as principais causas da precarização da força de trabalho no Brasil são a flexibilização, a desregulamentação dos direitos do trabalhador e a intensificação do trabalho. Neste caso, é exigida do trabalhador maior produção em menos tempo. 
Para Nozaki (2004), essa transformação trouxe a quebra das relações de estabilidade, carreiras e salários, bem como o uso, por parte dos empregadores, de estratégias como atualização e estímulo à participação dos trabalhadores nos lucros. Especificamente no mercado de trabalho do profissional de EF, a flexibilidade foi uma das formas utilizadas para acentuar a exploração da força de trabalho através do chamado profissional liberal.

Para a manutenção da lógica de produção capitalista, necessita-se desta expansão, que acirra a divisão hierárquica do trabalho e intensifica a retirada de direitos da sociedade que vive do trabalho. Esta foi submetida nesta última reestruturação às transformações que caracterizam o processo de produção denominado toyotista. Para Mézàros (2009), essa divisão tem como função proteger os interesses vitais do sistema, assegurando a expansão contínua da extração do/sobre o trabalho.

A expansão da produtividade prolifera tanto na esfera material, isto é, nas atividades profissionais, comerciais e de serviços, quanto na dimensão imaterial, caracterizada, segundo Antunes (2002), pelas atividades intelectuais e cognitivas, que também necessitam produzir novos conhecimentos para produzir excedentes na sociedade regida pelas mercadorias. Estas mudanças geram, na dimensão imaterial dos grandes centros produtores, mutações nas finalidades da produção do conhecimento, desviando-se ainda mais do seu caráter útil para singelas quantidades mensuráveis.

\section{A PRODUTIVIDADE EXIGIDA NA VIDA ACADÊMICA}

Os valores que permeiam o modo de produção capitalista adentram os diferentes campos da vida social e afetam os modos de vida da classe trabalhadora, para além do tempo dedicado à venda da força de trabalho. No esporte, na educação, na cultura assiste-se a uma constante valorização do individualismo, da competição, da meritocracia, como elementos fundamentais da vida social.

No ensino superior e na pós-graduação brasileira esses valores têm sido adotados como parâmetro de classificação de instituições, de cursos, de professores, de estudantes. Não há dúvida sobre a necessária avaliação de qualquer processo de formação, independentemente do nível de ensino que seja analisado. Entretanto, essa avaliação deve servir para apontar os aspectos que precisam ser alterados, modificados ou melhorados, e não para fomentar um determinado tipo de produtividade acadêmica, cuja qualidade daquilo que cria pode ser bastante questionável por não responder às necessidades mais amplas da sociedade, por se pautar em parâmetros eminentemente quantitativos e por ser geradora de competição entre instituições de ensino.

Para Chauí (2003), há na universidade indícios da transposição da ordem vigente que se expressa nas necessidades de se atingir "metas" e alcançar índices 
de produtividade. Essa lógica faz com que docentes e discentes almejem uma produção com a finalidade de atingir objetivos individualizados para manter ou atingir determinadas posições no meio acadêmico. Não por acaso, há uma similaridade nesse modelo com a tendência de convencer os trabalhadores de outros setores a buscar a todo o tempo produzir em um tempo reduzido uma quantidade maior de produtos para conservar seu posto de trabalho.

Assim, características do modelo toyotista são fortemente sentidas na produção acadêmica. Metas são permanentemente definidas a estudantes e professores, que precisam buscá-las, sob o risco de serem desligados dos programas ou de serem expostos perante o grupo e taxados como improdutivos. Mesmo que a trajetória de um docente revele seu absoluto comprometimento com a universidade, essa é esquecida numa avaliação que apenas considera um triênio de um determinado tipo de "produção".

Certas exigências das instituições de ensino e de agências como a Capes mostram-se, não raramente, dignas de fábricas toyotistas [...] Nas universidades, como nas plantas industriais toyotistas, muitos dos que resistem a se adaptar sofrem retaliações e assédio moral. (PITA, 2010, p. 15)

Rodrigues (2007, p. 44) ao discutir os critérios utilizados pelos órgãos de fomento para selecionar projetos para obtenção de financiamento, afirma que "o sistema de produção atual pode ser indutor de um ciclo nada virtuoso, no qual são estimulados aqueles que publicam muito e não aqueles que produzem conhecimento com qualidade, se admitirmos que mais não significa sinônimo de melhor".

Uma expressão que recorrentemente é usada nas reuniões do programa de pós-graduação aqui analisado é "será preciso subir o sarrafo". Essa expressão, apoderada das provas de salto em altura no atletismo em que, quanto mais o atleta salta, maior é a elevação do obstáculo para que tente saltar mais, sugere que as metas precisam ser permanentemente elevadas.

Na pós-graduação, a apropriação da expressão "subir o sarrafo" tem como significado ampliar periodicamente as metas, de modo a exigir maior produtividade docente e auferir melhor pontuação na escala de pontuação da Capes. $\bigcirc$ desejo de alcançar melhor pontuação junto à Capes está diretamente relacionado aos benefícios obtidos, seja em recursos financeiros, em bolsas ou simplesmente com o status de pertencimento a um programa com maior nota.

Há evidências nas produções teóricas recentes de que a forma assumida pela produtividade acadêmica precisa ser repensada. Especificamente na EF destacam-se os estudos de Souza, Luzzi e Pereira (20 I0), Rodrigues (2007), Lovisolo (2007) e Ventura (20 l 0). Nessas investigações são abordados aspectos como o papel da 
universidade, os critérios de produtividade e as especificidades das diferentes linhas de estudo na EF.

A não valorização das três dimensões da formação universitária ensino-pesquisa-extensão, apontada por Souza, Luzzi e Pereira (20।0), nas avaliações da pós-graduação pode comprometer o papel do ensino superior brasileiro de contribuir para a transformaçãa social. $\bigcirc$ tripé ensino-pesquisa-extensão, assegurado constitucionalmente como obrigatório para que uma instituição se caracterize como universidade, deixa de ter relevância na formação acadêmica. $\bigcirc$ trabalho desenvolvido no âmbito da extensão tende a ser percebido como "perda de tempo", já que não gera produtos acadêmicos valorizados pelas agências de fomento. A questão é: como fica a necessária interlocução entre universidade e sociedade se essa dimensão da formação não é valorizada?

A impossibilidade dos pesquisadores de conhecerem o universo que exploram por conta da exigência de que um "um resultado é sempre um resultado e precisa ser publicado" é outro aspecto denunciado por Chaú-Berlink (2004). O autor chama a atenção para o lugar que ocuparão determinadas descobertas científicas que demandam longos prazos de investigação quando a avaliação da produção científica ocorre em intervalos curtos.

Nos estudantes, parece estar impregnada a ideia de que é preciso construir uma imagem "produtiva" junto ao corpo docente do programa, que sirva de referência para futuras indicações em outras esferas da vida acadêmica (concursos, outros níveis da pós-graduação, novas pesquisas e financiamentos). De acordo com Chauí-Berlink (2004), atividades que deveriam estar voltadas para a formação de indivíduos, para a compreensão e atuação no campo científico, "se transformaram numa pequenina indústria da publicação".

Toda a criatividade e a espontaneidade ligadas ao processo de publicação de um trabalho científico são substituídas por um automatismo amorfo, uma obrigação sem crítica que, como um cão que persegue loucamente a própria cauda, é incapaz de parar e questionar o que está sendo feito. (CHAUÍ-BERLINK, 2004, p. 59)

Essa pressão é um dos aspectos que leva à precarização do trabalho, produzindo tanto em estudantes quanto em professores um sofrimento que se expressa na ansiedade, no medo e na insegurança pela incerteza de permanecer ou não em um programa de pós-graduação.

Uma característica do modelo toyotista que pode ser trazida para este estudo é a existência da figura do (trabalhador) colaborador. Na esfera acadêmica, tanto professores quanto estudantes, embora tenham metas individuais, passam a ser responsabilizados pelo sucesso de um programa de pós-graduação, na medida em 
que o não cumprimento das metas individuais pode gerar prejuízos para o programa como um todo, que pode ser, inclusive, descredenciado junto à Capes.

\section{O QUE REVELAM OS ESTUDANTES DA PÓS-GRADUAÇÃO}

Todos os discentes do curso de pós-graduação investigado aceitaram participar do estudo, demonstraram satisfação com a possibilidade de expor suas opiniões sobre a vida acadêmica no mestrado e alguns afirmaram que estavam curiosos para ler o relatório final da pesquisa. Todos foram informados sobre os objetivos do estudo e, logo no início da gravação da conversa, avisados sobre o sigilo de suas identidades.

A partir das orientações de Triviños (2006), realizou-se a interpretação dos dados e a definição dos temas oriundos das informações levantadas que melhor respondiam aos propósitos da investigação. Foram, então, definidos os seguintes grupos de análise: o tempo para realização da pós-graduação; os critérios de produtividade; e as repercussões objetivas e subjetivas para a vida sob pressão.

A sistematização dos grupos de análise teve como base as questões apresentadas aos estudantes durante as entrevistas. As questões que mais diretamente contribuíram nas discussões deste texto foram as que abordavam: a) a relação entre o tempo disponível para a realização do curso e a qualidade do trabalho de pesquisa; b) a repercussão na vida dos estudantes das exigências dos critérios de produtividade que balizam a organização da pós-graduação stricto-sensu, considerando os diferentes campos do conhecimento que constituem a EF; c) a incorporação dos valores do modelo de produção vigente na pós-graduação a ponto de afetar a vida dos estudantes para além dos muros da universidade.

Os entrevistados revelaram que o prazo de permanência, o tempo dedicado e o nível de comprometimento do estudante com um curso estão entre os fatores que determinam a qualidade de sua formação. Nas últimas décadas, observou-se o encurtamento do tempo e o aligeiramento dos prazos para a realização de uma pós-graduação no Brasil. Essa é uma característica que afeta todas as áreas do conhecimento. Nas décadas passadas era possível usar vários anos para realizar um mestrado ou um doutorado, já mais recentemente, em especial nos cursos de mestrado, esse prazo foi reduzido, por orientação da Capes, na maior parte dos programas, para 24 meses.

No curso aqui investigado, os estudantes devem cumprir os créditos em disciplinas e elaborar e defender a dissertação dentro de 24 meses. Grande parte dos acadêmicos divide o tempo dedicado ao mestrado com o trabalho realizado em escolas e em outros locais, já que não há bolsas suficientes para todos. Entretanto, mesmo que o programa contasse com um número de bolsas que atendesse 
a todos os matriculados, provavelmente muitos acadêmicos não conseguiriam suprir todas as suas necessidades somente com os recursos disponibilizados pelas agências de fomento.

Para a maior parte dos entrevistados, o tempo para realização do mestrado é curto, ainda mais quando é dividido entre o estudo e o trabalho assalariado. A principal consequência apontada para esse problema é a menor qualidade dos relatórios finais de pesquisa apresentados no final do curso.

Eu acho dois anos pouco para desenvolver um trabalho de mais qualidade. Eu acho corrido dois anos, até porque tem o estudo pra fazer, tu tem coleta de dados, nem sempre é fácil coletar, nem sempre vai achar todo mundo disponível, aí tem mais as disciplinas pra fazer, tem gente que ainda vai trabalhar, porque não tem bolsa, eu acho dois anos pouco, poderia ser mais. (Fernanda)

O prazo de dois anos parece afetar mais ainda os discentes lotados em linhas de estudo na EF das ciências humanas, devido às características metodológicas de elaboração de uma pesquisa nessas áreas. Nota-se, inclusive, que muitos acadêmicos, apoiados por seus orientadores, abandonaram a defesa de um relatório mais amplo de pesquisa e passaram a elaborar um artigo já formatado nos moldes de um periódico científico. De acordo com Souza, Luzzi e Pereira (20 l 0, p. 49), trata-se de uma forma de produção que atende "aos critérios estabelecidos pelos órgãos de fomento e avaliação, mas que, por outro lado, não promovem, necessariamente, a formação de massa crítica".

Uma interpretação mais complexa da realidade possibilitada pela apropriação teórica cede lugar a análises muitas vezes aceleradas de dados levantados. No caso dos estudos realizados no campo das humanas, o risco de avaliações superficiais de dados é grande, já que a assimilação de determinadas bases teóricas exige a dedicação de um significativo tempo de estudo. É recorrente o discurso da desvalorização de estudos que demandam mais debate teórico, como se esse tipo de análise representasse $^{4}$ uma "perda de tempo". De acordo com Chauí-Berlink (2004, p. 60)

[...] como dizem os norte-americanos: publisch or perisch! Como se ouve aqui entre nós: "Publique, não perca tempo com detalhes teóricos. Depois você pensa melhor". Quando esse pesquisador irá pensar melhor? Ele foi criado desvinculado do embasamento crítico e do arcabouço teórico, ele não tem tempo para pensar.

Os estudantes lotados em linhas das ciências humanas, preocupados com a necessária compreensão da fundamentação teórica com a qual trabalham, reclamaram

4. É a mesma sensação identificada no tempo dedicado ao trabalho com a extensão universitária. 
da pressão sofrida para responder as exigências formais do programa e as cobranças para publicação de artigos.

Eu me sentia na pressão de ter que produzir. Tinha esta pressão e ainda tem, até tem um artigo que eu vou mandar pra revista, mas eu não me alienei a isso, claro que isso tem a ver com tudo aquilo que eu acredito. [...] e nesses 24 meses a gente não faz a pesquisa a gente tem os créditos para cumprir, e tem disciplinas que têm trabalhos pra fazer, leituras, então a gente não faz a pesquisa em dois anos, a gente faz as disciplinas e corre sem tempo, a gente, quando tem tempo, pega um pouco o trabalho, de madrugada, de noite. (Carla)

Nas entrevistas, os discentes expressam uma postura mais crítica em relação às exigências do programa, mas, por outro lado, preocupados com projetos futuros como a realização de concursos ou a própria continuidade na pós-graduação, cedem ao assédio do apelo hegemônico do acompanhamento do "ritmo de produção".

Mas assim como tu me perguntastes se os 24 meses são suficientes para se fazer um bom trabalho? Eu acho que pro bolsista mais ainda né, porque querendo ou não, tu tá recebendo um dinheiro que vem, eu vi assim, não sei mas eu acho que os bolsistas poderiam aproveitar melhor esta chance que têm, eu aproveitei, eu posso não ter divulgado muita coisa, porque o meu trabalho tá terminando agora, mas eu fiz dois trabalhos com ratos nesse meio tempo, eu consegui fazer bastante coisa, a gente só não publicou porque o orientador não teve tempo de revisar para mandar para a revista. (Priscila)

A lógica que regula os programas de pós-graduação é análoga ao modelo de produção vigente, em que, aparentemente, todos estão em igualdade de condições para galgar melhores posições no mercado de trabalho. Esta é uma questão importante para a EF, pois as condições de produção não são iguais nas diferentes áreas de pesquisa. Sobre esse debate, vale lembrar que a EF está lotada na Capes na grande área das ciências da saúde e, por essa razão, segue as determinações de produtividade desse campo do conhecimento.

Alguns estudos na EF são situados nas ciências biológicas e outros nas ciências humanas. A lotação ${ }^{5}$ na área biológica acaba por desconsiderar essa ambivalência na produção científica na EF e, por consequência, gera inúmeros problemas ${ }^{6}$ para discentes e docentes que desenvolvem seus estudos no campo das ciências humanas. No balanço que faz da produção do conhecimento na área, Ventura (20 l0, p. 188) defende a tese "de que os grupos que dominam ou que desejam dominar

5. De acordo com Ventura (20 I 0), há um prejuízo à diversidade epistemológica dos estudos na EF devido a sua localização na Capes na Grande Área das Ciências da Saúde. O autor chega a essa conclusão a partir da análise do Relatório do Colégio Brasileiro de Ciência do Esporte do $I^{\circ}$ Fórum Nacional Permanente de Pós-Graduação em EF.

6. Os principais problemas que podem aqui ser destacados são o reduzido número de publicações para o campo das humanas e o rebaixamento dos conceitos de periódicos desse campo quando avaliados na área da EF. 
os problemas da realidade têm mesmo como busca a dominação do pensamento no campo".

Não se trata de estabelecer uma crítica para possíveis mudanças no sentido de melhores conceitos para as revistas, ou alavancar a circulação de um número maior de periódicos nas ciências humanas, embora isso possa significar um grande avanço, mas questionar que significado tem esse tipo de avaliação e produção para o avanço científico no país e, naturalmente, para a melhoria das condições de vida da população.

Em relação aos critérios de produtividade estabelecidos pela Capes, as respostas ao estudo foram variadas. Alguns entrevistados encaram com naturalidade e acreditam que essa é a única forma de "obrigar" os programas a produzirem. Já outros entendem que tais critérios são nefastos à produção científica, por se basearem fundamentalmente em critérios numéricos e terem como referência de avaliação a área biológica.

É como eu tava te falando, é desigual, eu acho muito desigual, inclusive o número de professores aqui da faculdade, é uma questão que dificulta a área da produção das ciências humanas para as ciências biológicas, nessa área tem muito mais professores. (Fernanda)

No programa estudado, os docentes que desenvolvem seus estudos nas linhas da área biológica são maioria, consequentemente o número de discentes ingressantes nessas linhas é maior. Embora não seja foco desta investigação, esse é um dado importante, porque a predominância da qualificação, em nível de pós-graduação, em uma área provocará a concentração das discussões sob um tipo de interpretação na EF.

A produção do conhecimento na pós-graduação tem um papel político importante, pois traduz o tipo de debate e de trabalho que é realizado na área. Nesse sentido, conforme sugere Ventura (2010, p. 182), a questão é "saber a favor do que e de quem a produção na Educação Física brasileira encaminha seu acúmulo de conhecimentos, ou seja, que postulados a orienta: os do paradigma hegemônico ou, os do contra-hegemônico?"

As regras geradas pelo sistema de avaliação de currículos permitirão a sobrevivência na pós-graduação apenas daqueles que conseguirem atingir os critérios de produtividade. Como, no caso da EF, esses critérios são mais vantajosos para um determinado campo do saber, são os grupos situados nesse campo que se multiplicarão, "tornando-se uma espécie hegemônica num determinado futuro" (RODRIGUES, 2007, p. 44).

Dois outros aspectos precisam ser considerados nesse debate. $O$ primeiro deles é a quase inexistência de periódicos com conceito A (na escala de avaliação 
da Capes) para publicação pelos estudiosos do campo das humanas. $\bigcirc$ segundo refere-se à possibilidade de publicação de um artigo por um grande grupo de pesquisadores, algo que, nos espaços do campo das humanas, pelas próprias características da área, é limitado.

Eu sentia assim, que não tem justificativa, se tu ganhas pra isso tens que produzir, como se fosse muito fácil pra um profissional como vocês que têm disciplina na graduação, pós-graduação, convites para bancas e tu ter que produzir parelho com o que o pessoal da saúde produz é complicado [...\} por mais que eu produza 2 ou 3 artigos por ano dificilmente vou conseguir publicar os 3 em uma revista que te dá 100 pontos cada um. (Maira)

Como efeito da dificuldade para atingir a pontuação no Qualis Capes, relatado pela discente, muitos docentes têm recorrido a outros programas de pós-graduação para realizar suas pesquisas ou simplesmente abandonam o trabalho nesse nível de ensino.

Esta ordem classificatória dada pela quantidade de produções em um triênio não leva em consideração fatores como o histórico do docente ao longo de sua vida na universidade ou a atuação em atividades de extensão, por exemplo, aspectos que são de suma importância para a formação acadêmica.

A superficialidade da produção científica, gerada pela pressão para produzir muito e rápido, também foi apontada pelos entrevistados como um problema na EF. Trata-se de uma complexa distorção cultural, gerada pelo aumento da competição, que confere maior relevância ao número de publicações em relação ao conhecimento produzido (RODRIGUES, 2007).

Os discentes têm constatado que, em alguns casos, a assimilação da exigência de produção se expressa no desmembramento dos trabalhos em partes que gerem vários textos.

Isso é um assunto meio complicado. Essa exigência de produção é o ponto que eles nos acharam para nos cobrar um serviço, uma carga de trabalho, uma meta de trabalho. Mas que eu acho? Ela é importante, ela é fundamental, até para o desenvolvimento da ciência como um todo. Mas, é um troço que isso fica, como eu vou te dizer: alguém tropeçou na calçada ali, monta um projeto de pesquisa sobre o tropeço, faz uma pesquisa meia boca, tenta publicar e publica, então fica uma moeda de produção. Hoje em dia tem muita gente que produz artigo pra vencer essas metas, mas obviamente aqui na faculdade tem trabalhos e laboratório que eu vi que trabalham sério, que a produção vem ao natural. Eu acho que, às vezes, as pessoas são obrigadas a fazer esses trabalhos e aí começam a surgir coisas que não têm muita qualidade. (Artur)

Percebeu-se, ao longo desta pesquisa, que é dispensada nas reuniões e conversas pouca atenção ao conteúdo dos estudos ou aos resultados atingidos com 
as investigações. Em contrapartida, grande valor é atribuído à pontuação alcançada com as publicações. Afinal, o que é mais importante na produção científica? $\bigcirc$ número de pontos que se alcança com publicações ou a repercussão na vida social dos resultados encontrados em determinada investigação?

A pós-graduação segue as leis do próprio modelo de produção de mercadorias. Dessa forma, a inversão de valores tem caracterizado o trabalho nesse nível de ensino, em que parece pouco interessar o que se faz e até mesmo os meios utilizados nessa produção. Para Ventura (20 I 0, p. I89), "as exigências para se chegar a um determinado patamar (as avaliações) e, pior, para se manter em algum lugar, tramam pressões que causam comportamentos nem sempre compatíveis com o nível de intelectualidade que reside nos programas".

No caso da EF, é possível questionar se a atividade científica, produzida no campo acadêmico, tem contribuído para qualificar as condições de trabalho ou a prática nas diversas áreas que a compõe. De acordo com Souza, Luzzi, Pereira (2010, p. 50), os "PPG-EF têm dirigido pouca atenção para a atividade pedagógica e ao conhecimento direcionado aos problemas profissionais da área. $\bigcirc$ desfecho será docentes produtivos, mas pouco criativos e despreocupados com o objeto da investigação".

As exigências de produtividade afetam objetiva e subjetivamente os estudantes. No primeiro caso, no tempo exigido para a dedicação ao curso. Em um período de 24 meses é preciso cumprir créditos, elaborar uma dissertação, participar de eventos, publicar artigos em periódicos e realizar estágio de docência. A discente Maira relata que, no segundo ano, as preocupações se intensificam devido à sobrecarga gerada pelo tempo definido para o término da elaboração da dissertação.

\footnotetext{
É integral, eu fico na frente do computador 10, 12 ou 14 horas por dia, isso por 3 meses, e isso direto. Antes o trabalho era mais braçal, de organização dos dados através dos questionários. Mas nesses últimos 3 meses tem sido bastante cansativo, teve uma semana ai que eu fiquei 3 dias sem conseguir escrever nada, tava apavorada, chega uma hora que você esta sobrecarregada demais, tua cabeça já leu demais, já escreveu demais e você começa a revisar não vendo seus erros. (Maira)
}

No segundo caso, nos sentimentos e sensações decorrentes desses processos, que chegam a interferir nas relações pessoais dos discentes. Quando os acadêmicos não estão objetivamente debruçados sobre a pesquisa, a análise de dados e a escrita, estão a todo tempo pensando neste trabalho, o que desencadeia insônia, ansiedade, angústia.

mestrado ocupa assim, divido com os meus filhos, digamos assim, 100\% da minha vida. Eu trabalho todas as tardes no mestrado, a hora que meus filhos vão pra escolinha, todas as tardes de segunda a sexta e sábados de manhã, e depois às I I da noite quando 
meus filhos vão dormir, das I I da noite até meia noite I, 2, 3 da manhã. Eu sonho com o mestrado, às vezes eu perco o sono e volto a trabalhar, ai de manhã eu fico com os meus filhos, sábado e domingo, domingo eu não consigo pegar, porque eu não tenho empregada, aí eu fico pensando eu tinha que fazer esse trabalho, aquela questão, como vou resolver aquela questão, eu já tinha que ter terminado isso. O meu tempo tá acabando e não estou conseguindo fazer, tá faltando tempo. (Carla)

Todo o conjunto de sensações a que estão submetidos os discentes, desde que se torna conhecida a aprovação na pós-graduação, se acentua pela própria concorrência interna, que não raramente está ligada a benefícios financeiros ou a progressão na pós-graduação. Os alunos confessam que há controle, exigência e verificação por parte dos próprios colegas, o que desencadeia atrito entre os mesmos.

É uma máquina de produção, né! Não é só uma exigência dos professores, dos docentes, a gente também é exigida um monte assim, eu sentia essa pressão, não do meu orientador, porque ele nunca me exigiu nada. Mas os colegas, e depois da bolsa pior ainda. Sabe aquele negócio da concorrência, de um querer engolir o outro. Por isso é que eu te digo, minha dificuldade não foi do trabalho em si, minha dificuldade foi essa do convívio com esse tipo de atitude, e as pessoas não têm esse tipo de amadurecimento, tu podes crescer assim como eu também posso, eu não preciso querer te afundar para crescer, e isso tem aqui, e muito. (Patricia)

Entre os entrevistados, identificou-se certa indignação com as características da pós-graduação. Entretanto, a tolerância e a resignação prevalecem entre os estudantes. Se, por um lado, as exigências são dificilmente atingidas e produzem sofrimento para os discentes, por outro são tratadas com naturalidade, como se não houvesse outra opção nesse nível de formação.

\section{CONSIDERAÇÕES FINAIS}

Os dados deste estudo revelam que a avaliação do modelo de pós-graduação implantado no Brasil é indispensável para analisar que futuros docentes e pesquisadores são formados a cada ano. $\bigcirc$ debate sobre o tipo de formação e a concepção de ciência que têm pautado os programas precisam ser ampliados.

É também urgente uma avaliação do trabalho realizado na pós-graduação pela comunidade acadêmica da EF. Os dados dos programas de pós-graduação no país são reveladores do enfraquecimento das ciências humanas, com uma participação reduzida dos docentes dessa área. Isso pode produzir na EF efeitos nefastos, na medida em que somente um tipo de interpretação da realidade é privilegiado.

No que tange aos acadêmicos, é preciso considerar um conjunto de aspectos que precariza a formação em um curso de mestrado. A delimitação do tempo 
e a mensuração quantitativa de índices de produção foram identificadas como as principais causas da pressão sofrida pelos discentes.

Na opinião dos participantes da pesquisa, os critérios de avaliação adotados na pós-graduação são questionáveis, em especial, pela lotação da EF na grande área das ciências da saúde. Entretanto, são tímidas as manifestações contrárias a esse modelo dentro do programa aqui analisado. Parece haver certo receio de que ocorra algum tipo de represália àqueles que apresentam resistência ao modelo de avaliação hegemônico na área.

É necessário analisar se realmente a universidade necessita se submeter a processos fabris para a criação e consolidação dos programas de pós-graduação. Aprofundar essa discussão e transformar as considerações deferidas nesta produção são desafios a serem alcançados por pesquisadores que têm despendido tempo para denunciar a exploração do trabalho docente.

Especificamente em relação à produção científica, é imprescindível uma reflexão sobre o que tem sido feito com o vasto material produzido na área, para identificar se a "quantidade" exigida pelas agências de fomento de fato reflete em um melhor trabalho realizado na sociedade.

\section{The Production Requirements for Students in Postgraduate Studies}

ABSTRACT: This study aimed to identify what are the implications of the demands of productivity in the academic field for students from a postgraduate studies and how these objectively and subjectively affect their daily lives. In the investigation we adopted a qualitative methodological approach, with reference to the search for understanding the object studied and its explanation in the social practice (TRIVIÑOS, 2006). We chose to carry out a case study, the understanding that this type of qualitative research would be most appropriate to achieve the purposes for the questions raised. The delimitation of time and quantitative measurement of production were identified as major causes of reduced quality of training in a postgraduate. Keywords: Postgraduate Studies; Production; Physical Education; Research.

\section{Los requisitos de producción para los estudiantes de posgrado}

RESUMEN: Este estudio tuvo como objetivo identificar cuáles son las implicaciones de las exigencias de la productividad en el campo académico para los estudiantes de un curso de postgrado y cómo objetiva y subjetivamente afectan sus vidas diarias. En la investigación que hemos adoptado un enfoque metodológico cualitativo, con referencia a la busca de la comprensión del objeto de estudio y su explicación en la práctica social (TRIVIÑOS, 2006). Hemos elegido para llevar a cabo un estudio de caso, el entendimiento de que este tipo de investigación cualitativa sería más apropiada para alcanzar los objetivos de las cuestiones elegidas. La delimitación del tiempo y la medición cuantitativa de las tasas de producción fueron identificadas como las principales causas de disminución de la calidad del postgrado. Palabras Clave: Postgrado; producción; Educación Física; investigación. 


\section{REFERÊNCIAS}

ANTUNES, R. Adeus ao trabalho? ensaio sobre as metamorfoses do mundo do trabalho. São Paulo: Cortez, 2002.

BOSI, A. P. Feios, sujos e malvados: intensificação do trabalho docente e produtividade acadêmica. Universidade e Sociedade, Brasília, n. 47, p. |33-148, fev. 201 I.

BOSI, A. P. Precarização do trabalho docente no Brasil: novas e velhas formas de dominação capitalista (1980-2005). Universidade e Sociedade, Brasília, n. 38, p. 42-59, jun. 2006.

CHAUI, M. A. Universidade pública sob nova perspectiva. Revista Brasileira de Educação, São Paulo, n. 24, p. 5- I5, set./dez. 2003.

CHAUÍ-BERLINK, J. G. A quem interessa o produtivismo científico? Teoria e Debate, São Paulo, n. 60, p. 58-6I, nov./dez. 2004.

LOVISOLO, H. R. "Levantando o sarrafo ou dando um tiro no pé": critérios de avaliação e qualis das pós-graduações em Educação Física. Revista Brasileira de Ciências do Esporte, Campinas, v. 29, n. I, p. 23-33, set. 2007.

MAUÉS, O. O produtivismo acadêmico e o trabalho docente. Universidade e Sociedade, Brasília, n. 4I, p. 21-32, jan. 2008.

MÉZÁROS, I. O século XXI: socialismo ou barbárie. São Paulo: Boitempo, 2009.

NOZAKI, H. T. Educação Física e reordenamento no mundo do trabalho: mediações da regulamentação da profissão. 2004. 399 f. Tese (Doutorado) - Faculdade de Educação, Universidade Federal Fluminense, Niterói, 2004.

PEIXOTO, M. I. H. Arte e grande público: a distância a ser extinta. São Paulo: Autores Associados, 2003.

PITA, M. Estresse laboral, assédio moral e burnout marcam produtivismo. Revista Adusp, São Paulo, n. 48, p. 14- 21, set. 2010.

RODRIGUES, L. O. C. Publicar mais, ou melhor? o tamanduá olímpico. Revista Brasileira de Ciências do Esporte, Campinas, v. 29, n. I, p. 35-48, set. 2007.

SGUISSARDI, V. Produtivismo acadêmico. In: OLIVEIRA, D. A.; DUARTE, A. M. C.; VIEIRA, L. M. F.. (Org.). Dicionário de trabalho, profissão e condição docente. Belo Horizonte: Ed. Da UFMG, 2010.

SILVA JR., J. R. Produção do conhecimento imediato, mercantilização institucional e fundo público. Revista Espaço Acadêmico, Maringá, v. 9, p. 167-177, 2010.

SILVA JR., J. R.; SGUISSARDI, V. Trabalho intensificado nas federais: pós-graduação e produtivismo acadêmico. São Paulo: Xamã, 2009. 
SOUZA, E. R.; LUZZI, A.; PEREIRA, B. O fordismo acadêmico na Educação Física. Revista Brasileira de Ciências do Esporte, Florianópolis, v. 32, n. 2/4, p. 43-57, dez. 2010.

STAKE, R. Estudos de caso em pesquisa e avaliação educacional. Educação e seleção: revista da Fundação Carlos Chagas, São Paulo, n. 7, p. 5-18, jun. 1983.

TREIN, E.; RODRIGUES, J. O canto de sereia do produtivismo científico: o mal-estar na Academia e o fetichismo do conhecimento-mercadoria. Universidade e Sociedade, Brasília, n. 47, p. 133-148, fev. 2011.

TRIVIÑOS, A. N. S. Introdução à pesquisa em ciências sociais: a pesquisa qualitativa em educação. São Paulo: Atlas, 2006.

VENTURA, P. A Educação Física e sua constituição histórica: desvelando ocultamentos. 2010. 208 f. Tese (Doutorado) - Faculdade de Educação, Pontifícia Universidade Católica de Goiás, Goiânia, 2010.

Recebido em: | 4 dez 20 | | Aprovado em: 20 out. 2012 Endereço para correspondência: Valdelaine Mendes Rua: Barão de Butuí, 28I apto. 702 Bairro: Centro Pelotas/RS CEP:960I0-330 